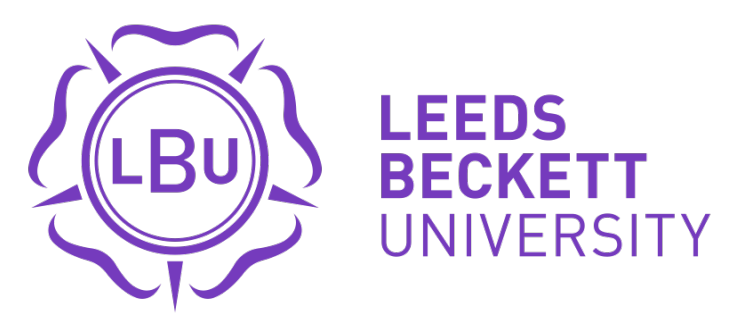

Citation:

Chisman, E and Brooks, R (2018) The interplay between being and belonging through meditation: a grounded theory methods study. Journal of Occupational Science. ISSN 1442-7591 DOI: https://doi.org/10.1080/14427591.2018.1514320

Link to Leeds Beckett Repository record:

https://eprints.leedsbeckett.ac.uk/id/eprint/5267/

Document Version:

Article (Accepted Version)

This is an Accepted Manuscript of an article published by Taylor \& Francis in Journal of Occupational Science on 11 September 2018, available online: http://www.tandfonline.com/10.1080/14427591.2018.1514320

The aim of the Leeds Beckett Repository is to provide open access to our research, as required by funder policies and permitted by publishers and copyright law.

The Leeds Beckett repository holds a wide range of publications, each of which has been checked for copyright and the relevant embargo period has been applied by the Research Services team.

We operate on a standard take-down policy. If you are the author or publisher of an output and you would like it removed from the repository, please contact us and we will investigate on a case-by-case basis.

Each thesis in the repository has been cleared where necessary by the author for third party copyright. If you would like a thesis to be removed from the repository or believe there is an issue with copyright, please contact us on openaccess@leedsbeckett.ac.uk and we will investigate on a case-by-case basis. 
The interplay between being and belonging through meditation: A grounded theory methods study

Ellen Chisman and Rob Brooks

ORCID ID 0000-0002-7335-7831 and 0000-0002-7104-0099

School of Clinical and Applied Sciences, Leeds Beckett University, Leeds, UK

Corresponding author: Ellen Chisman, School of Clinical and Applied Sciences, Leeds

Beckett University, City Campus, LS1 3HE, +44 (0)113 8125636,

eschisman@gmail.com 


\section{The interplay between being and belonging through meditation: A grounded theory methods study}

The relationship between the concepts of being and belonging, that is understanding how connecting with oneself (being) interacts with connecting with others (belonging), remains to be studied in detail. In addition, the processes that take place in meditation, as an occupation, remain relatively unstudied in occupational science literature. The purpose of this qualitative study was to explore what the experience of meditation can reveal about the interplay between being and belonging, with a focus specifically on meditation as practised in the Buddhist Triratna tradition. Interviews were conducted with six meditators and the data analysed using constructivist grounded theory methods. Findings revealed that being and belonging were experienced as interconnected and coarising. Belonging provides learning opportunities for how to be, and being provides time and space to work out how to belong with others. The interplay between being and belonging through meditation is captured in the category "growing as individuals, with others; becoming more fully human". This study is thought to be the first that details the relationship between being and belonging. It is argued that occupational science should further utilise this conceptualisation for a richer and more authentic understanding of occupation. Examples of the implications for research design and data analysis are given, as well as recommendations for further research.

Keywords: being, belonging, meditation, grounded theory

\section{Introduction}

The four dimensions of occupation (doing, being, belonging, and becoming) have been utilised in occupational science discourse in order to aid the understanding of occupation (Hitch, Pépin, \& Stagnitti, 2014a; 2014b). According to Hitch et al.’s (2014) review, however, only a small proportion of studies address the interdependent nature of the concepts, and instead have a particular occupation, condition, or circumstance at the forefront. Surveying the literature, since that review was published, reveal similar findings. Links between being and belonging have been suggested, implied, or can be inferred (Blank, Finlay, \& Prior, 2016; Bratun \& Asaba, 2008; Carra, Fortune, Ennals, D’Cruz, \& Kohn, 2017; Kay \& Brewis, 2017; Riley, 2008; Thomas, Gray, \& McGinty, 2017), but no explicit attention to the relationship between the two concepts was found. 
A reason for this neglect could be that despite Wilcock highlighting the interdependence of the dimensions, the necessity of dividing them in An Occupational Perspective of Health $(2006,2015)$ has encouraged research focused in this segregated way (Hitch et al., 2014b). In addition, in Western settings, being has been portrayed as an individualistic sense of self rather than a collective view of self in relation to others (Hitch et al., 2014a). This individualistic conceptualisation could be a factor limiting understandings of the interplay between being and belonging. Exploration of the connected nature of being and belonging is needed to comprehend the complexity of occupation and for the theoretical framework to be authentic to lived experience (Hitch et al., 2014b). This current study has contributed to this need through data gathered from meditators of a Triratna Buddhist tradition.

\section{Being and belonging}

Being is a dimension of occupation understood as "how people feel about what they do" (Wilcock \& Hocking, 2015, p. 180), and includes notions around meeting our needs to be creative, challenged, find meaning, build self-esteem, and be motivated. Being is also used in the literature regarding existing and the need for space and time to just "be" (Hitch et al., 2014a). Belonging is about connecting, and the need to connect with others. It includes notions around a sense of familiarity, affinity, commitment, attachment, and acceptance (Hammell, 2014). Belonging helps us to understand our place in the world (Wilcock \& Hocking, 2015).

There is a sense in which our being is part of our belonging, perhaps needed for it. In 1999 Wilcock defined being as "being true to ourselves [...] and to what is distinctive about us to bring to others as part of our relationships and to what we do" (p. 5, italics added). Yet since then there has been no explicit exploration in the literature of the link between these two concepts, with the exception of Hitch et al.'s 
(2014b) review. They proposed that the relationship between being and belonging is an association between one's identity as an occupational and human being, and sense of connectedness. Hitch et al. drew on Bratun and Asaba's (2008) study on the Chinese practice of Qi Gong. This practice involves the combination of physical and mindfulness exercises (Qigong Institute, 2017). For participants in this study, finding calm and becoming more aware and present helped them open up and connect more easily with people in the group. However, the focus of this study was the formation of a community through occupation, and the links between being and belonging were not made explicitly in those terms or discussed in detail.

Associations between being and belonging have been suggested or can be inferred from some existing studies in occupational science and therapy. In Riley's (2008) study on creative textile-making, a sense of self (linked to being, and briefly doing and becoming) and a collective sense of self (linked to belonging) were developed by engaging in this occupation. Riley explained that individuals bring their own personal background that bears on collective action and its meaning, also that the guild is a context where the individual self is informed and we come to know who we are. However, the link between belonging and being is not explicitly made, despite using the four dimensions as a framework in the paper.

Co-existence between doing and each of the other dimensions, and also between becoming and belonging was noted and outlined by Carra et al. (2017) in the context of scholarly identity and practice among occupational therapy academics. Yet links between being and belonging in discussion of identity were not made. Blank et al. (2016) focused on belonging in the context of dual diagnosis, and proposed dimensions of belonging. This included "embodied feelings of belonging" - an example being of a participant who said self-harmed belonged to them - and how connection with these 
feelings could be promoted through relaxation and meditation. The concept of being was not included in the paper.

In 2014 Hitch et al. identified that literature that addresses multiple dimensions of occupation tended to view them in isolation rather than the relationships between them. Since then, Kay and Brewis (2017) explicitly acknowledged the "dynamic transaction" between the dimensions, and explored the relationships between doing, being, and becoming in relation to tattooing; yet belonging was still addressed separately. The associations between connecting with others and connecting with self were not made, despite discussing concepts such as self-esteem.

A recent study on achieving well-being through occupations by the homeless (Thomas et al., 2017) identified three themes: survival, self-identity, and social connectedness, with connections between each. The findings support existing thinking in occupational science that self-identity is influenced by interactions with others, and feelings of connection can be affected by individual factors such as esteem, values, and priorities (see Thomas et al., 2017). However, a thorough understanding of the relationship between being and belonging remains to be given. No literature could be found in the fields of occupational science or therapy that explicitly studied in detail the interplay and processes between being and belonging.

\section{Meditation}

Some occupational scientists have argued for a greater understanding of a collectivist view of self in relationship with others (Duncan, 2009; Iwama, 2006; Turpin \& Iwama, 2011). Hitch et al. (2014b) similarly argued that studying Eastern philosophies and occupations has the potential to uncover more about the interdependence between being and belonging, because of the importance placed on interconnections with others. 
Elliot (2011) reported that meditation had not been attended to in the occupational science discourse. The researchers here found this still to be the case. The occupation of meditation has the potential to offer unique insight into how being and belonging may relate from an Eastern perspective depending on the type/approach to meditation studied. This study focused on the Buddhist tradition of Triratna. This is a modern tradition/movement, founded by Sangharakshita, who drew on various older traditions, including Mahayana, Theravada, and Tibetan (Subhuti, 1994). Although founded in England, the movement is practised worldwide, including countries such as India (thebuddhistcentre.com, n.d). In Triratna, meditation is used for Samatha (tranquillity, calm through mindfulness) and Vipassana (insight into reality, through contemplation) (Sangharakshita, 1996, 1998; Subhuti, 1994). Two practices used for both purposes by meditators are referred to in the findings of this study. These are Mindfulness of Breathing (Vessantara, 2005) which focuses on different aspects of the breath, and Metta-Bhavana (Vessantara, 2006) which focuses on extending feelings of metta (loving-kindness, compassion) and equanimity to oneself, people dear, neutral, and challenging to you, and other livings beings (e.g. in the same city).

Triratna embodies perspectives and beliefs that can be understood as "Eastern"; the interrelated nature of all things, non-dualist distinctions (e.g. mind/body, form/emptiness), and a non-permanent self (Sangharakshita, 2009; Thompson, 2012); although caution is required to not over-simplify what is understood by "Eastern" since there are differences between schools of thinking and cultures in the East, e.g. Indian and Chinese, or Buddhist and Hindu (Thompson, 2012). However, Sangharakshita (2009a) asserted that when religious aspects are distinguished from cultural ones, Buddhism transcends the conditions of East and West. The meditation practices used in Triratna include a focus on being, paying attention to one's state, and 
to relationships with others. The Qi Gong study outlined above demonstrates how such practices can bring awareness to mechanisms taking place between self and others. Studying experiences of these meditators provided the potential to identify the processes involved in connection with self and others, and the influence of (particular) Eastern perspectives.

\section{Methods}

\section{Research question}

This study sought to answer the question: In the experiences of Triratna meditators, what is the nature of the interplay between connecting with self (being) and with others (belonging)?

\section{Study design}

To answer the research question, a qualitative grounded theory approach (Charmaz, 2014) was adopted. Grounded theory is suited to the study of occupation because it explores social processes that shape human interaction and behaviour (Birks \& Mills, 2015), and these processes unfold over time through engagement in occupation (Nayar, 2012). Using grounded theory methodology is a way of gaining a better understanding of occupational processes (Nayar, 2012); in the case of this study, the interplay between being and belonging, or self and others, through engaging in meditation. Symbolic interactionism underpins some versions of grounded theory - including the approach of Charmaz (Birks \& Mills, 2015), focusing on individuals as socially constructed beings and where realities of the world are constructed through interacting with the environment and other beings (Charmaz, 2014; Stanley \& Cheek, 2003).

Charmaz's (2014) constructivist grounded theory methods were used in this 
study. With this approach, categories and theories are constructed by the researcher; recognising and accepting that researchers bring their own experiences and background to the research process (Birks \& Mills, 2015; Charmaz, 2014; Otkay, 2012). These influences have the potential to bring new insights to existing theories, providing methodologies are consistently and rigorously followed (Charmaz, 2014). Constructivist grounded theory was consistent with the ontological position of the primary researcher; that the phenomena in question are constructed (Bryman, 2016; Charmaz, 2014), and her epistemological position; where data analysis and formulation of the findings are interpreted by the researcher (Charmaz, 2014; Otkay, 2012). The primary researcher is a practitioner and member of a Triratna group, which assisted understanding of participants' responses and experiences. A number of reflective strategies were used to monitor this personal involvement including a reflective journal to scrutinise the researcher's influences on the study and consider alternative perspectives (Birks \& Mills, 2015; Mruck \& Mey, 2012). Memoing was also used. For example the memo "positioning the researcher" (Birks \& Mills, 2015) was written, reflecting on her choice of topic and questions (Maso, 2003), and identifying assumptions brought and responses to the research and interview questions (Mruck \& Mey, 2012). This was referred to during data analysis. The secondary researcher scrutinised the interview schedules and developments of the model and storyline as a non-practitioner.

Data were gathered via in-depth individual interviews. Individual semistructured interviews were used because there was specific content to cover, but allowed depth in responses and new concepts/issues to arise (Charmaz, 2014; Denscombe, 2014). Field notes were also kept as potential data sources (Birks \& Mills, 2015; Charmaz, 2014). An interview schedule was devised, and an iterative approach used as appropriate to a grounded theory methods study where the schedule was reviewed 
between rounds of data collection and coding stages (Bryman, 2016; Charmaz, 2014;

Denscombe, 2014).

\section{Recruitment and selection}

Sequential purposive sampling was used, where the sample is added to with participants suitable to answer the evolving research questions (Bryman, 2016; Morse, 2012). In the final round, theoretical sampling was used, whereby two ordained members with many years of meditation experience were selected to aid the developing analysis (Charmaz, 2014; Morse, 2012). Therefore, the selection criteria were somewhat flexible depending on the data needs that arose, and are shown in Table 1.

<Insert Table 1 here>

A small sample was justified by using a relatively homogenous population, focusing on a niche area with small scope (Bryman, 2016; Hagaman \& Wutich, 2017), and in the event participants generally expressed similar responses to each other which enabled production of categories. A total of six participants were recruited, all identifying as White British ethnicity. Member checking was done by returning to two previous participants to check for resonance of emerging analysis (Charmaz, 2014), resulting in eight interviews. Recruitment was through posters and the e-newsletter of a Triratna Buddhist Centre in England distributed by a gatekeeper, who was a Trustee of the centre. On expressing interest in taking part, by directly emailing the primary researcher, an information sheet and consent form were sent to participants, along with a simplified interview schedule (i.e. without probes and prompts). Signed consent was obtained by the researcher before each interview commenced. Ethical approval was obtained from Leeds Beckett University (ref. 27952). Table 2 summarises participants' demographic information collected at the start of each interview. 
<Insert Table 2 here>

\section{Data collection and analysis}

A pilot interview was conducted with the primary researcher to test the first interview schedule. Examples of the questions asked included:

- Why do you meditate?

- What is it like when you meditate with others?

- How is meditation different from other parts of your day or things you do?

- What effect on you do you think meditation has (immediately after and longterm)?

No substantial changes were made following the pilot, and this interview formed part of the first round of data collected and analysed. Interviews with participants 1 and 3 , and the return interview with participant 5 , took place over the phone. Research suggests that data collected via telephone can be of equal quality (Bryman, 2016). The remaining interviews were conducted face-to-face at the Centre from which the participants were recruited. The primary researcher conducted the interviews, which lasted 40-65 mins.

Data collection and data analysis were recursive; a standard feature of grounded theory methods (Birks \& Mills, 2015; Bryman, 2016; Charmaz, 2014). All interviews were digitally audio recorded and interviews 1-5 were transcribed verbatim. Interview 6 and the return interviews were more of a discussion using emerging models and storyline, so substantial field notes and a recording were kept to use at that stage rather than transcriptions to systematically code. NVivo 10 (QRS International, n.d) was used for initial and focused coding, organising and de-limiting categories. Coding was 
conducted by the primary researcher. Gerunds were used for code names to help detect processes and actions (Charmaz, 2014); an example is given in Table 3.

<Insert Table 3 here>

Essential grounded theory methods were employed. Constant comparison was done between data sets, categories, and between data and categories to keep a close fit between analysis and data (Dey, 2012; Otkay, 2012). An example can be found in the memo excerpt below, showing comparison between interviews and other categories for "reducing doing".

- This means you become more focussed on the things you are doing ("like a lazar", interview 3)

- This produces a momentum which is "helpful" (interview 4) in situations after meditation where you need to focus, and also where you need to be aware of many things, suggesting you can cope and process all this better. Also links to increasing awareness. Suggested in interview 3 as well, for activities afterwards such as reading

- Interview 4 links it to integration that continues after. It seems now that it is focussing that leads to integration. So, reducing doing - focussing - integration

Developing a model and explanation of the phenomena taking place was aided by drawing relational diagrams between categories (Buckley \& Waring, 2013). Memoing was done throughout, which became increasingly analytic, and highlighted links between categories and properties thereof (Birks \& Mills, 2015; Charmaz, 2014).

In the theoretical coding stage, existing concepts and theory that aided analysis were considered, and incorporated providing they fitted the data (Charmaz, 2014; Dey, 2012; Hernandez, 2009). An example is "integrating", which came from both participants' responses and Triratna literature (Sangharakshita, 1996; 1998; Subhuti, 1994). As suggested by Birks and Mills (2015) for grounded theory studies, a storyline was written (and re-written numerous times) to aid analysis, and to add explanatory power to the model for later participants to study (Charmaz, 2014). Field notes were kept after each interview, as a record of non-verbal communication or environmental 
factors that may affect the data (Birks \& Mills, 2015; Charmaz, 2014); for example, annotations made by participants on the model presented in later interviews. Sampling and analysis ended when no new categories emerged and relationships between categories had been identified (Dey, 2012; Charmaz, 2014; Morse, 2012).

\section{Findings}

With all participants, being and belonging were found to be experienced as dynamic and inter-related. Being influenced belonging and vice versa; belonging provided learning opportunities for how to be, and being provided time and space to work out how to belong with others. Participants saw their development as individuals as interconnected with others.

A model of the interplay found between being and belonging is presented in Figure 1. The process outlined is iterative; experiences of being and belonging is influenced by feedback from further meditation practice and daily life. To remain consistent with the ontological position of constructivist grounded theory, the model is seen as a representation of a truth which can be developed following further research (Charmaz, 2014; Sbaraini, Carter, Evans, \& Blinkhorn, 2011). Excerpts from the storyline are given to add explanatory power to the model.

<Insert Figure 1 here>

\section{Being}

The categories in this part of the model are shown in a linear sequence with relational arrows. Participants described that one experience followed from another (e.g., space was created as a result of the preceding elements). 


\section{Letting go of doing/resting the mind}

As participants move through the process in Figure 1, practising meditation and integrating new ways of being and belonging into daily life, a shift takes place. This is from trying hard to do things or for things to happen, to letting go and allowing things to happen. Participant 6 described this as an attitudinal change: "you could $d o$ the mindfulness of breathing or you could be the mindfulness of breathing; it's a complete attitude" and that this comes with time and practice. It is represented in the model as a change from reducing doing to letting go of doing, and from focussing the mind to resting the mind on something, e.g. sense experience. The findings suggest that the elements under "being" are what someone tries to do as a beginner practitioner, but that later these are allowed to arise during meditation practice.

\section{Facilitated by intentions and practices used}

What participants gain from their meditation is influenced not simply by which practice is done but also the intention that is bought to the practice. Earlier participants talked about using particular practices for specific ends such as the Mindfulness of Breathing (Vessantara, 2005) for calming down and sleep, or the Metta-Bhavana (Vessantara, 2006) for dealing better with a difficult relationship and how they respond to others. Later participants distinguished between using the two broad types of meditation: Samatha (tranquillity), and Vipassana (insight). Particular practices can be used to help cultivate one type or the other, but the intention bought to a practice also matters.

\section{Belonging}

Participants drew on the aspects given in this box to varying extents. Some used the immediate group at the Centre as an integral part of supporting and developing their 
practice, and providing experiences of belonging. For others, the group at the Centre played less of a role, practising more alone or with a range of people from different contexts. All participants expressed belonging to a group of some sort. This included a wider group or community, such as: other meditators, other Buddhists, and even with those they had never met but knew they were sharing in something with them. In the "being and belonging" box, this sense of belonging extends even more widely to a connection with other human beings and living things. As described by participant 3 :

... I think [the Metta-Bhavana practice has] made me feel... I don't want to... cause unnecessary cruelty to animals, and other beings particularly. Some of the retreats I've been on have been like... a space where it's a bit like sort of being completely shaken up, both in respect to oneself and in respect to, 'cause we're just part of... everything else aren't we?

\section{Being and belonging}

Participants expressed that the aspects shown in this box were inter-connected, and how they arose or co-arose varied at times, both between participants and for the same individual.

\section{Gaining understanding/insight}

Although an intention to gain insight can be brought to the meditation, and contemplative practices used, some participants said that insights can also be spontaneous and things just come to them. Participant 6 distinguished between understanding and "insight", the latter being stronger; discovering something that impacts on you and the way you are/live. All participants expressed, in various ways, how it was important that what happened "on the cushion" (participants 5 and 6) - i.e. during meditation - translated or was "integrated" (participant 6) into life. Examples of 
these insights and their impact are given under the following two categories. The relationship between being and belonging is seen in that the insights gained impacted on feelings/beliefs about and actions towards others. For example, some participants talked about challenging fixed ideas about "self", and then seeing that they also had fixed ideas about others which could be challenged e.g. that someone "is annoying" (participant 2). Insights such as these allow perceived barriers or strains between self and others to be reduced.

Connecting with myself/connecting with others, and opening/dropping of boundaries

Participants expressed "self" as a difficult and disputed concept in Buddhism and personal views. "The nature of my being" sought to cover the range of views expressed and included such insights around the nature of self. One of the most common and important set of experiences reported is captured in "opening of boundaries". Participants talked about recognising other points of view and accepting individual differences better, while coming to see the similarities between themselves and other livings things. Empathy and compassion and the example of suffering were often mentioned. However, both ordained members talked about moving beyond dualism, comparisons, and judgements. This shift is captured by "dropping of boundaries". Participant 6 also talked about a move away from "I language" and an orientation with themselves at the centre. All participants talked about these understandings and insights bringing connection with others. Participant 5 stated:

It's hard to separate those things out really [referring to 'connecting with myself' and 'connecting with others' on the diagram]. So I think I discover who I am more deeply in relationship to others, and I discover what others are when I'm in more connection with myself. 
This quote reflects interplay between connecting with oneself and connecting with others. Connecting with the nature of their own being and the being of others enables the participants to appreciate comparisons between themselves and other living beings, in some cases dropping comparisons or categorisation. Also vice versa, opening/dropping of boundaries supports further feelings of connection or belonging with themselves and others.

Growing as individuals, with others; becoming more fully human

The social process is depicted in this category. Participants expressed that through meditation they were working on how they live in the world as individuals (also talking explicitly or implicitly about developing themselves), including how they live with other humans and living things. Examples given included: becoming vegan, giving up alcohol, not engaging in gossip, and communicating more positively, effectively, and meaningfully. The examples were given with the view that these behaviours better reflected who they were, and a better way to live with and in the world - supported for some participants by Buddhist teachings upheld in Triratna e.g. Five Ethical Precepts and Noble Eight-fold Path (Sangharakshita, 1998, 2009b). Later participants explicitly stated that they could not conceive being and belonging as completely separate (at this stage an emerging model including these specific terms was discussed). For one participant, the whole process being studied was seen to be about "becoming more fully human", which was confirmed by later participants. "By becoming more individual we become more connected... and in becoming more connected we become more individual" (participant 5). Participant 6 expressed it as:

Doing this [pointing at 'Being' on the model] more means you can do that [pointing at 'Belonging'] more authentically... the more you are able to be 
yourself, the more you are able to relate as a true individual, rather than someone who's got something to gain or lose from being in the group.

It was suggested that feelings of belonging reduce perceived pressure to be a certain way, and that individuals can be more comfortable with who they are. Participant 6 described this whole process as never complete; you are "re-becoming" and learning different ways of being and belonging.

\section{Discussion}

The findings of this study contribute to a further understanding of the interplay between being and belonging. It is believed to be the first study in literature on occupation to propose a model of the relationship between being and belonging, as experienced through Triratna meditation. This research confirms the interdependent nature of being and belonging (Hitch et al., 2014b; Wilcock, 2006; 2015). The nature is such that each provides learning opportunities to experience the other. From a symbolic interactionist perspective, participants made sense of themselves through their interactions with others, and constructed understandings of others using their sense of self. This social process is depicted in the category Growing as individuals, with others; becoming more fully human.

For the participants in this study, meditation was seen to have the purpose of personal development, but crucially this was seen in a collectivist sense; that who one is connects to and is measured by how one behaves in relation to others (or belongs) in the world. Eastern perspectives (here Triratna Buddhism), specifically around a collective concept of being, non-dualism, and impermanent self, illuminate this process and reveal experiences of being and belonging as interdependent. The division between "I" and "them" is lessened, and participants come to understand themselves and where they fit 
with others.

The findings give an example of experiencing self and being (through meditation of a specific Buddhist tradition) differently, in moving away from a “centrally situated self" (Iwama, 2006, p. 161). The sort of person they wanted to be(come) involved consideration of what is right/good/best as living interconnected with others, motivating acts around jobs, diet, hobbies, communicating, mental and exhibited responses to others and situations. This way of being is echoed in Kondo's (2004) study on Japanese collective culture. In this current study, reading, attending talks, and activities aside from meditation were mentioned by some participants as influencing how they understood what was going on in meditation and in their lives. However, it was doing meditation where participants actually experienced connection and interplay between being (self) and belonging (others) and this informed and was informed by experiences in daily life. Their experiences of being and belonging through meditation impacted on their occupational lives, in terms of the meaning, purpose, and values around what they do. It also affected points of life transition, such as changing careers or the ending of a long-term relationship. However, these broader aspects have not been investigated here, and would be areas to expand on in future research about the interplay between being and belonging.

Iwama (2006) highlighted the need to be critical about the concepts used in occupational science for cultural relevance. Iwama argued that in Japanese culture the concepts of doing, being, belonging, and becoming would be better placed in the order of belonging and being first, with doing last (Turpin \& Iwama, 2011). It is argued here that there is also a need for further conceptualisation of being and belonging as intimately interconnected and co-arising. This change in the way occupational science 
considers being and belonging would have important implications for how occupations are analysed, and result in deeper understanding.

Returning to some of the literature discussed at the start of this paper serves to give examples of the impact of this change in conceptual thinking. Blank et al. (2016) argued that self-isolation may not be a sign of distress but a means of managing that distress. This could be further understood as self-isolation not necessarily being a disconnection from others, but as time for being (time out, recharging, reflecting) so direct experiences with others can then be managed better, or connections felt stronger. Carra et al.'s (2017) exploration of identity and support in the academy could be enhanced in terms of the inter-connecting factors between being and belonging affecting identity, and therefore additional ideas on how academics and practitioners can be supported in this arena.

Conceptualising being and belonging as co-arising has implications for the way research is designed, data analysed and findings presented when using the dimensions of occupation as a framework. Swan et al. (2018) is a recent example of a study using this framework; in this case, exploring meaningful occupation with iPads for older adults and staff in a mental health residential setting. The analysis and findings were organised into the four separate dimensions. This was despite Hitch being one of the authors; Hitch et al. (2014b) having previously argued that our understanding of occupation is limited if we use the dimensions in this way. The authors here agreed with this view. Another example demonstrates how our conceptual frameworks influence analysis, even if the dimensions themselves are not explicitly used. Borges da Costa and Cox (2016) conducted a grounded theory study on meaning in Circle Dance. Categories identified were divided broadly along benefits gained around self, under the category "unique experience of being engaged in circle dance" (e.g. self-development, feeling 
transformed), and benefits gained in regards to others under the category "feeling part of the ethos of circle dance" (e.g. fostering connections, supportive environment). The connections between the main categories are not explored. Conceptualising being and belonging as co-arising could open up new insights when analysing data.

\section{Limitations}

All the participants in the sample were from a White British background. A more ethnically diverse sample could affect findings where other backgrounds may influence different experiences of being and belonging. Crucially, for this study, the participants were engaging in an Eastern occupation and faith group with Eastern connections, but had grown up in a Western culture. Since this study was looking at what Eastern perspectives could tell us about experiences of being and belonging, findings and conclusions could be further developed by studying a sample from such a population. This would include widening the scope of the research beyond Triratna and Buddhism, to other cultures and faith traditions. It is acknowledged that the findings and model are situated in a particular context (Charmaz, 2014); yet, the findings presented here are still relevant to Western countries, where take-up of Eastern philosophies and mindfulness meditation practices is growing (Edenfield \& Saeed, 2012; Farias \& Wikholm, 2015).

\section{Recommendations for future research}

As the model and storyline show, participants felt that what one gains or experiences from meditation is influenced by the practices and intentions used. One participant expressed that secular mindfulness meditation can have limitations depending on how it is delivered, for example, if focused around the individual and what he or she can gain, rather than developing compassion to others and impacting on how one lives with others. The findings of this study are based on participants engaging with meditation 
within a specific tradition with particular (“Eastern”) views. More research would need to be done to understand the experiences of those with "Western" perspectives and whether the interplay of being and belonging were experienced differently, perhaps as less tightly connected. Similarly, research on populations from other "Eastern" cultures and meditation traditions would be needed.

\section{Conclusions}

This study has developed an understanding of the interplay between being and belonging. Being and belonging were found to be interconnected; influencing each other and co-arising. The social process identified showed that participants made sense of themselves through their interactions with others, and constructed understandings of others using their sense of self. Meditation supported "growing as individuals, with others; becoming more fully human". A model of the interplay between being and belonging through meditation was presented. Since this study is situated in a particular context, research on a range of populations and meditation practices would serve to test the model in other settings.

Consideration of Eastern perspectives, specifically the Buddhist Triratna tradition, and the understudied occupation of meditation has contributed to the depth of knowledge about the dimensions of being and belonging. The authors argue that occupational science should further utilise a conceptualisation of being and belonging as co-arising and interdependent for a richer and more authentic understanding of occupation. This would help address current conceptual limitations affecting research design and data analysis in occupational science, with the potential to bring new insights to the discipline. 


\section{Acknowledgements}

The researchers wish to thank the participants who took part in this study, and the Gatekeeper who supported the ethics and recruitment processes.

\section{Disclosure}

No funding was received for the research. The authors declare no competing interests.

\section{References}

Birks, M., \& Mills, J. (2015). Grounded theory: A practical guide (2 ${ }^{\text {nd }}$ ed.). London, UK: SAGE.

Blank, A., Finlay, L., \& Prior, S. (2016). The lived experience of people with mental health and substance misuse problems: Dimensions of belonging. British Journal of Occupational Therapy, 79(7), 434-441. doi:10.1177/0308022615627175

Borges da Costa, A., \& Cox, D. (2016). The experience of meaning in circle dance. Journal of Occupational Science, 23(2), 196-207. doi:10.1080/14427591.2016.1162191

Bratun, U., \& Asaba, E. (2008). From individual to communal experiences of occupation: Drawing upon Qi Gong practices. Journal of Occupational Science, 15(2), 80-86. doi:10.1080/14427591.2008.9686613

Bryman, A. (2016). Social research methods (5th ed.). Oxford, UK: Oxford University Press.

Buckley, C. A., \& Waring, M. J. (2013). Using diagrams to support the research process: Examples from grounded theory. Qualitative Research, 13(2), 148-172. doi: $10.1177 / 1468794112472280$

Carra, K., Fortune, T., Ennals, P., D’Cruz, K., \& Kohn, H. (2017). Supporting scholarly identity and practice: Narratives of occupational therapy academics. British Journal of Occupational Therapy, 80(8), 502-509. doi:10.1177/0308022617700653

Charmaz, K. (2014). Constructing grounded theory ( $2^{\text {nd }}$ ed.). London, UK: SAGE. Creswell, J. (2014). Research design: Qualitative, quantitative, and mixed methods approaches $\left(4^{\text {th }}\right.$ ed.). London, UK: SAGE. 
Denscombe, M. (2014). The good research guide: For small-scale social research projects $\left(5^{\text {th }}\right.$ ed.). Berkshire, UK: Open University Press.

Dey, I. (2012). Grounding categories. In A. Bryant \& K. Charmaz (Eds.), The SAGE handbook of grounded theory ( $4^{\text {th }}$ ed., pp. 167-190). London, UK: SAGE.

Duncan, M. (2009). Human occupation in the context of chronic poverty and psychiatric disability. Unpublished doctoral dissertation, Stellenbosch University, Stellenbosch, South Africa. Retrieved from https://scholar.sun.ac.za/bitstream/handle/10019.1/1120/duncan_human_2009.p df;sequence $=1$

Edenfield, T., \& Saeed, S. (2012). An update on mindfulness meditation as a self-help treatment for anxiety and depression. Psychology Research and Behaviour Management, 5, 131-141. doi:10.2147/PRBM.S34937

Elliot, M. (2011). Being mindful about mindfulness: An invitation to extend occupational engagement into the growing mindfulness discourse. Journal of Occupational Science, 18(4), 366-376. doi:10.1080/14427591.2011.610777

Farias, M., \& Wikholm, C. (2015). The Buddha pill: Can meditation change you? London, UK: Watkins Publishing Ltd.

Hagaman, A., \& Wutich, A. (2017). How many interviews are enough to identify metathemes in multisited and cross-cultural research? Another perspective on Guest, Bunce, and Johnson’s (2006) landmark study. Field Methods, 29(1), 23 41. doi:10.1177/1525822X16640447

Hammell, K. W. (2014). Belonging, occupation, and human well-being: An exploration. Canadian Journal of Occupational Therapy, 81(1), 39-50. doi:10.1177/0008417413520489

Hernandez, C. (2009). Theoretical coding in grounded theory methodology. Grounded Theory Review, 8(3) [Online]. Retrieved from http://groundedtheoryreview.com/2009/11/30/theoretical-coding-in-groundedtheory-methodology/

Hitch, D., Pépin, G., \& Stagnitti, K. (2014a). In the footsteps of Wilcock, part one: The evolution of doing, being, becoming, and belonging. Occupational Therapy in Health Care, 28(3), 231-246. doi:10.3109/07380577.2014.898114 
Hitch, D., Pépin, G., \& Stagnitti, K. (2014b). In the footsteps of Wilcock, part two: The interdependent nature of doing, being, becoming, and belonging. Occupational Therapy in Health Care, 28(3), 247-263. doi:10.3109/07380577.2014.898115

Iwama, M. (2006). The Kawa model: Culturally relevant occupational therapy. Edinburgh, UK: Churchill Livingstone Elsevier.

Kay, H., \& Brewis, C. (2017). Understanding tattooing from an occupational science perspective. Journal of Occupational Science, 24(3), 351-364. doi:10.1080/14427591.2016.1241186

Kondo, T. (2004). Cultural tensions in occupational therapy practice: Considerations from a Japanese vantage point. American Journal of Occupational Therapy, 58(2), 174-184.

Maso, I. (2003). Necessary subjectivity: Exploiting researcher's motives, passions and prejudices in pursuit of answering 'true' questions. In L. Finlay \& B. Gough (Eds.), Reflexivity: A practical guide for researchers in health and social sciences (pp. 41-51). Oxford, UK: Blackwell Science.

Morse, J. (2012). Sampling in grounded theory. In A. Bryant \& K. Charmaz (Eds.), The SAGE handbook of grounded theory ( $4^{\text {th }}$ ed., pp. 229-244). London, UK: SAGE.

Mruck, K., \& Mey, G. (2012). Grounded theory and reflexivity. In A. Bryant \& K.

Charmaz (Eds.), The SAGE handbook of grounded theory ( $4^{\text {th }}$ ed., pp. 515-538). London, UK: SAGE.

Nayar, S. (2012). Grounded theory: A research methodology for occupational science. Journal of Occupational Science, 19(1), 76-82. doi:10.1080/14427591.2011.581626

Otkay, J. (2012). Grounded theory [ebook]. doi:10.1093/acprof:oso/9780199753697.001.0001

Qigong Institute. (2017). Home page. Retrieved from https://www.qigonginstitute.org/

QRS International. (n.d). What is nVivo? Retrieved from http://www.qsrinternational.com/what-is-nvivo

Riley, J. (2008) Weaving an enhanced sense of self and a collective sense of self through creative textile-making. Journal of Occupational Science, 15(2), 63-73. doi:10.1080/14427591.2008.9686611 
Sangharakshita. (1996). A guide to the Buddhist path (2 $2^{\text {nd }}$ ed.). Birmingham, UK: Windhorse.

Sangharakshita. (1998). What is the Dharma? The essential teachings of the Buddha. Birmingham, UK: Windhorse.

Sangharakshita. (2009a). The essential Sangharakshita. Boston, MA: Wisdom Publications.

Sangharakshita. (2009b). Living ethically. Birmingham, UK: Windhorse.

Sbaraini, A., Carter, S., Evans, W., \& Blinkhorn, A. (2011). How to do a grounded theory study: A worked example of a study of dental practices. BMC Medical Research Methodology, 11(128), 1-10. doi:10.1186/1471-2288-11-128

Stanley, M., \& Cheek, J. (2003). Grounded theory: Exploiting the potential for occupational therapy. British Journal of Occupational Therapy, 66(4), 143-150. doi:10.1177/030802260306600403

Subhuti, D. (1994). Sangharakshita: A new voice in the Buddhist tradition. Birmingham, UK: Windhorse.

Swan, J., Hitch, D., Pattison, R., Mazur, A., Loi, S., Westphal, A., \& Bolton. K. (2018). Meaningful occupation with iPads: Experiences of residents and staff in an older person's mental health setting. British Journal of Occupational Therapy. Advance online publication. doi:10.1177/0308022618767620

The Buddhist Centre. (n.d). Becoming a friend. Retrieved from https://thebuddhistcentre.com/text/becoming-friend

The Buddhist Centre. (n.d). Our history. Retrieved from https://thebuddhistcentre.com/text/our-history

Thomas, Y., Gray, M., A., \& McGinty, S. (2017). The occupational wellbeing of people experiencing homelessness. Journal of Occupational Science, 24(2), 181-192. doi:10.1080/14427591.2017.1301828

Thompson, M. (2012). Eastern philosophy: Teach yourself. London, UK: Hachette UK. Turpin, M., \& Iwama, M. (2011). Using occupational therapy models in practice: A field guide. Edinburgh, UK: Churchill Livingstone Elsevier.

Vessantara. (2005). The art of meditation: The breath. Cambridge, UK: Windhorse. Vessantara. (2006). The art of meditation: The heart. Cambridge, UK: Windhorse. 
Wilcock, A. (1999). Reflections on doing, being and becoming. Australian

Occupational Therapy Journal, 46, 1-11. doi:10.1046/j.14401630.1999.00174.x

Wilcock, A. (2006). An occupational perspective of health $\left(2^{\text {nd }}\right.$ ed.). Thorofare, NJ: SLACK incorporated.

Wilcock, A., \& Hocking, C. (2015). An occupational perspective of health. Thorofare, NJ: SLACK incorporated.

Table 1. Participant selection criteria

Table 2. Participant demographics

Table 3. Coding example

Figure 1. Model of the interplay between being and belonging through meditation 